\title{
In response to: "Cement or Calcitonin for Coccyx Fractures"
}

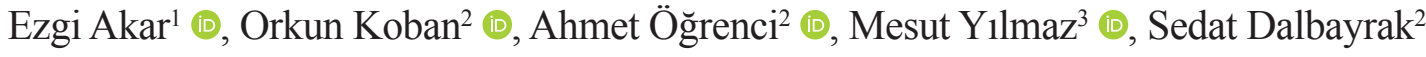 \\ 'Department of Neurosurgery, Haydarpaşa Numune Training and Research Hospital, Istanbul, Turkey \\ ${ }^{2}$ Department of Neurosurgery, Okan University School of Medicine, Istanbul, Turkey \\ ${ }^{3}$ Department of Neurosurgery, Neurospinal Academia, Istanbul, Turkey
}

\section{To the Editor,}

We thank Dr. Patrick Foye and his colleagues for their interest in our article "Polymethylmethacrylate cement augmentation of the coccyx (coccygeoplasty) for fracture: A case report" (1). They have stated their concerns about our paper in their Letter to the Editor. We gave our answers based on their comments.

Treatment of osteoporotic coccyx fractures by polymethylmethacrylate (PMMA) injection has been reported in the literature before and termed as coccygeoplasty (2). Coccydynia is not a rare condition, and several patients may benefit from PMMA or cement augmentation (that is coccygeoplasty). Many conservative methods have been applied to treat the patient's pain. Our patient was first treated with nonsteroidal anti-inflammatory drugs (NSAIDs), and doughnut pillows were recommended. Owing to the persistence of the patient's pain in his follow-up after 2 weeks, pericoccygeal local anesthetic agents and steroid injections were administered, but they did not relieve the pain (3). Coccydynia can be controlled by conservative methods, such as physical therapy, manipulation of the coccyx, analgesic treatments (NSAIDs, acetaminophen, opioids, and so on), and U-wedge or doughnut-shaped coccygeal cushions. As Dr. XXX stated, it is possible to treat a coccyx fracture with calcitonin (4). According to some publications, calcitonin administration has been used to treat acute pain after vertebral fracture and may also accelerate fracture healing (5). However, in some groups of coccydynia cases, which are less frequently observed in practice, conservative methods are not sufficient (approximately $10 \%$ of the cases). Another cause of pain in these patients is instability owing to acute or subacute fracture. Therefore, it is not surprising that coccydynia may not be relieved by calcitonin or other conservative methods, especially in patients with instability.

Interventional methods can be applied in patients whose pain does not regress with conservative methods. These methods are caudal epidural steroid injections, recurrent pericoccygeal local anesthetic agents and/or steroid injections, ganglionic parasympathetic nerve blocks, and selective radiofrequency ablation of the coccygeal nerve procedures. Dean et al. (2) have considered that conservative methods remained insufficient in treating coccydynia mainly caused by osteoporotic fractures and instability that it caused and recommended coccygeoplasty method to control pain in such cases; our case supported this idea. This technique can be rapidly and safely applied to a patient with osteoporotic coccyx fracture who has refractory pain $(1,2)$. The advantage of the coccygeoplasty method is that it is a successful and rapid method in pain control, early mobilization can be achieved, the morbidity of the patient is lesser, and the length of hospital stay is shorter.

There is still no method that can be considered as the standard in treating coccydynia. Coccydynia is usually controlled by conservative measures, such as physical therapy, manipulation of the coccyx, analgesic treatments, calcitonin treatment, and coccygeal cushions. However, these methods may be insufficient for treating osteoporotic coccyx fractures, especially in an unstable fracture. For the treatment of retractable pain in acute or subacute osteoporotic coccyx fractures, coccygeoplasty is recommended as a good and easy method.

Author Contributions: Concept - E.A., A.Ö.; Supervision - S.D., M.Y.; Resources - A.Ö., O.K.; Data Collection and/or Processing - A.Ö.; Analysis and/or Interpretation - E.A., A.Ö.; Literature Search - E.A., O.K.; Writing Manuscript - E.A.; Critical Review - S.D., M.Y.

Conflict of Interest: The authors declare no conflicts of interest.

\section{REFERENCES}

1. Akar E, Koban O, Öğrenci A, Yılmaz M, Dalbayrak S. Polymethylmetacrylate Cement Augmentation of the Coccyx (Coccygeoplasty) for Fracture: A Case Report. Balkan Med J 2020;37:348-50. [Crossref]

2. Dean LM, Syed MI, Jan SA, Patel NA, Shaikh A, Morar K, Shah O. Coccygeoplasty: Treatment for fractures of the coccyx. J Vasc Interv Radiol 2006;17:909-12. [Crossref]

3. Lirette LS, Chaiban G, Tolba R, Eissa H. Coccydynia: An overview of the anatomy, etiology, andtreatment of coccyx pain. Ochsner J 2014;14:84-7.

4. Marinko LN, Pecci M. Clinical decision making for the evaluation and management of coccydynia: 2 case reports. J Orthop Sports Phys Ther 2014;44:615-21. [Crossref]

5. Foye PM, Shupper P, Wendel I. Coccyx fractures treated with intranasal calcitonin. Pain Physician 2014;17:E229-E233

Address for Correspondence: Ezgi Akar, Haydarpasa Numune Training and Research Hospital, Department of Neurosurgery, Istanbul, Turkey

e-mail: ezgiaycicek@gmail.com

Received: August 7, 2020 Accepted: August 21,2020 •DOI: 10.4274/balkanmedj.galenos.2020.2020.8.34-reply

Available at www.balkanmedicaljournal.org

ORCID iDs of the authors: E.A. 0000-0002-8582-2948; O.K. 0000-0002-4721-0502; A.Ö. 0000-0002-7580-0227; M.Y. 0000-0001-8633-7883; S.D. 0000-0001-9538-5190.

Cite this article as:

Akar E, Koban O, Öğrenci A, Y1lmaz M, Dalbayrak S. In response to: “Cement or Calcitonin for Coccyx Fractures”. Balkan Med J 2021;38:64

Copyright@Author(s) - Available online at http://balkanmedicaljournal.org/ 